\title{
Improving sustainability in healthcare with better space design quality
}

\author{
M. F. Castro, R. Mateus \& L. Bragança \\ C-TAC, Department of Civil Engineering, University of Minho, Guimarães, Portugal
}

\begin{abstract}
The hospital project contains different aspects from the most common projects of residential, offices or services buildings. In common buildings, sometimes the user and the client are the same and when they are not, setting the requirements is not difficult since they are common to most inhabitants. In the case of hospital buildings this is not the reality and the project team is usually hired for the purpose of designing a building that includes different spaces and different users, such as doctors, nurses, patients, visitors, cleaning staff, administrators, and others. In this sense it is important to combine different spatial needs, which are always subject to constant changes throughout the period of building operation due to: new features; innovations; enlargement needs; and new healthcare treatment methods. This paper discusses the importance of the design and organization of space quality in the overall sustainability of a hospital building and how this aspect is evaluated in BSA tools.
\end{abstract}

\section{PATH TO SUSTAINABILITY}

\subsection{Hospital buildings}

The hospital buildings, not because they are more abundant in the territory, but because they are large consumers of natural resources and energy, should be a major focus of study in the evaluation process of the buildings life cycle (Guenther \& Vittori, 2008). The activities implied to the healthcare industry require a lot of energy for heating, refrigeration, etc. On the other hand it is necessary to take into account the use of renewable and non-renewable resources, disposable products, toxic substances and the production of a large quantity of waste (Short \& Al-Maiyah, 2009).

The health sector has a strong influence on the economy of nations and their policies, incorporating a group of buildings where the quality of the indoor environment is quite significant. The impacts of this type of buildings are more significant than any other because they are directly related to human health (Guenther \& Vittori, 2008). The operation of these equipment for 24 intensive hours, the high number of movement of people, the existence of distinct work zones with different energy needs, the existence of different functions such as treatment, research, rehabilitation, health promotion and disease prevention, the need for the existence of systems strategic reserve of equipment for constant supply of energy, and size of facilities, are key points that differentiate these from other types of buildings and make it a specific case study (Johnson, 2010).
Healthcare providers are not serving patients but serving people. They should design and deliver services to meet the needs of normal people at the most difficult times in their lives (Clark \& Malone, 2006).

The hospital project, more than any other, requires a number of concerns with the satisfaction and well being of working teams, patient, administrative staff and other officials. This is a project where all basic design principles (rather generalized and taken into account in the act of designing common buildings) should be considered with the increased responsibilities, since the users' satisfaction and well being demands are more sensitive. The basic design concerns usually considered are: the climate where the building is built; access to solar radiation; the local topography; the program of the building and the interaction between the various elements of the design team; the necessary flexibility and enlargement capacities; the security; the efficiency in the development of activities; the adaptability to new I\&D (Dias, 2004).

In this context its possible to say that the design phase is the most comprehensively addressed part of the life cycle in most sustainable building guidelines and evaluation methods (Dias, 2004). The design and the space organization are very important for different areas and can be decisive in environmental, economic and social development of the whole building. Therefore this study is about hospital architecture and how the project design quality can be fundamental for the well being of people and for the sustainability of construction. 


\section{SPACE DESIGN QUALITY}

\subsection{The contribution of space design to the sustainable hospital buildings}

Healthcare is one of the most complex and rapidly changing industries. It is continually transformed by new technologies, technique, pharmaceuticals and delivery systems (Boone, 2012). In this concern, it is a fact that the hospital architecture incorporates a development project that has as main concerns the adequacy of technological advances in medicine, compliance with rules and regulations (that seek to ensure the quality of designed environments), the complexity and flexibility required for the project and the high cost of premises. This means that the designer often forgets or not gives the adequate importance to sustainable principles that this type of project should follow (Shaw et al, 2010). Consequently the construction of this type of buildings needs to incorporate this evolution and the spaces design can be the way to improve healthcare. The architectural design of the space, its organization, operation and configuration, allows these buildings to respond and adapt positively to the needs for which they are designed. At an early stage, a good investment in their flexible design reduces the need for further improvements (Johnson, 2010).

Analysing the indicators and parameters of the Building Sustainability Assessment (BSA) tools, specifically oriented to hospital buildings, it is possible to assess how important is the use of these methodologies in the architecture design phase to promote the existence of more sustainable buildings in the future. Many of these parameters are easily answered through the spatial and volumetric organization of indoor and outdoor spaces. Therefore it is important to encourage the architects to incorporate these concerns in their projects, avoiding solving future problems resulting from the addition of equipment or other solutions that increase energy consumption, water or other resources, even human. Most times, sustainability assessments are used to comparatively classify the buildings. Nevertheless it is of increasingly importance that such methods are regarded as ordinary work tools in all project phases.

The design phase incorporates many decisions, such as the use of materials, choice of equipment, networks, infrastructure, among others, Nevertheless this paper is focused in the design of effective space, comprising options of building implantation, composition and spatial organization of buildings. Table 1 show some examples of spatial and volumetric organization taken in buildings of recognized quality in terms of sustainability.

Table 1. Example of design options in case studies

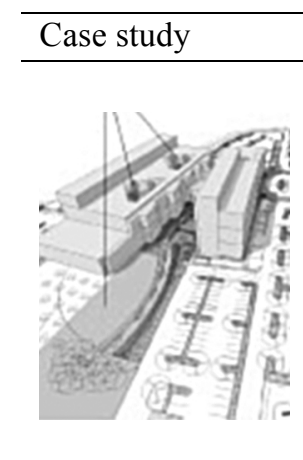

Description

Providence Newberg Medical Centre

Recognition: US Green Building Coun-

cil LEED (Gold level); Hospitals for a

Healthy Environment (H2E) - Environ-

mental Leadership Award (2007).

Design option: to implant the building

in two volumes in " $\mathrm{V}$ " shape. It favors

the green spaces, energy efficiency, visu-

al comfort and rainwater use.

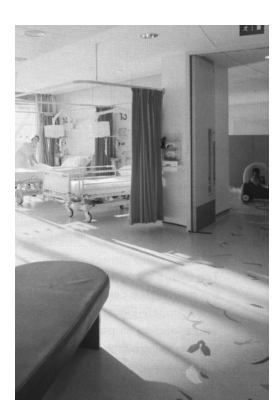

Evelina Children Hospital

Recognition: NHS Building Better

Health Care Award for Hospital Design,

Nov. 2006; Royal Institute of British Ar-

chitects design competition.

Design options: to remove the partition

walls between the rooms and the circula-

tion areas. It decreases the footprint, in-

creases the net floor area and allows

greater comfort in use by users.

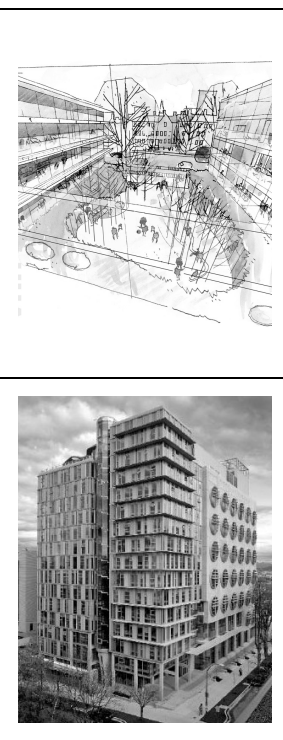

Kaleidoscope, Lewisham Children and

Young People's Center

Recognition: Firm won initial CABE

design competition.

. Design options: the plan facilitates deep penetration of daylight and moves the operable windows away from the heavily trafficked urban streetscape.

\section{BC Cancer Agency Research Centre}

. Recognition: Canada Gren Building

Council LEED (Gold level).

. Design options: the central atrium spine separates different areas from inpatient units. The atrium provides daylight to occupied workspaces, which line the upper floor.

\section{Boulder Community Foothills Hospital} . Recognition: First hospital certified by US Green Building Council LEED, in

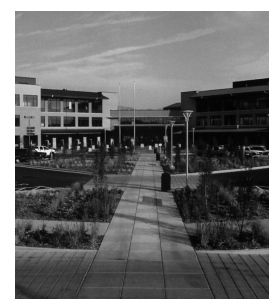
the E.U.A. (Silver level); distinction in 2006 Hospitals for a Healthy Environment (H2E) - Environmental Leadership Award.

. Design options: to reduce the car parking area and to create adequate parking areas and paths for bicycles, in order to encourage the use of alternative transportation.

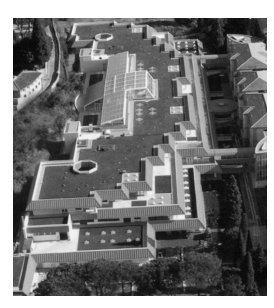
Meyer Children's Hospital Recognition: EU Hospitals Project. Design options: have features vegetated roofs with skylights and light tubes bring daylight deep into the interior. The building barely disrupts the landscape it appears to emerge from. 


\subsection{Building sustainability assessment tools for healthcare}

All over the world there is a growing number of sustainability assessment tools developed for the building sector and oriented for new constructions, existing buildings and refurbishment/rehabilitation operations. Inside these three groups, most assessment tools are specifically oriented for different type of buildings. In the context of hospital buildings the most well known tools are: BREEEM Healthcare, LEED for Healthcare and Green Star - Healthcare (BREEAM, 2013; LEED, 2013; GBCA, 2013). In addition to these, DGNB is developing a specific methodology for hospitals that is not finished yet, and CASBEE have a system for new construction that includes the hospital buildings in the category of residential buildings. Nevertheless the CASBEE tool does not specifically address this type of buildings, but is one tool with different specifications for residential and no-residential buildings. For this reason, this study is focused on BREEAM Healthcare, LEED for Healthcare and Green Star - Healthcare.

The three abovementioned tools have a system of evaluation based in points that are divided over different categories, each of which is based in a series of evaluation parameters (Sauders, 2008). Although there are some differences between these tools, they share the main areas of assessment. Analysing the indicators of each tool it is possible to conclude that there is no sustainability categories directly related with space design quality. Nevertheless there are some sustainability parameters that are indirectly related with that principle.

It should also be noted that an exceptional answer to the category Innovation in Design (that allows getting an extra score in all tools) allows correcting a worst performance in other sustainability categories. Credits for innovative performance are awarded for comprehensive strategies, which demonstrate quantifiable sustainability benefits not specifically addressed by other sustainability categories. Table 2 presents the sustainability parameters of the abovementioned tools that are directly influenced by the indoor and outdoor spaces design quality. Figure 1 shows with light grey the relevance (in percentage) of these parameters in the overall sustainable score.

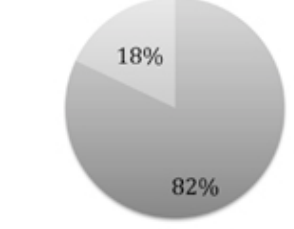

BREEAM Healthcare

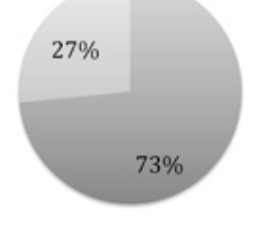

LEED for Healthcare

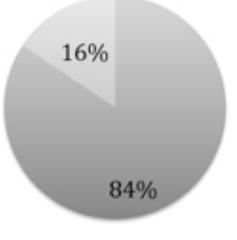

Green Star - Healthcare
Figure 1. The relevance of outdoor and indoor spaces' design quality (in percentage) in the overall sustainable score (represented in light grey).
Table 2. Sustainability parameters that are directly influenced by the indoor and outdoor spaces' design quality

\begin{tabular}{|c|c|c|c|c|}
\hline \multirow[t]{2}{*}{ Category } & \multirow[t]{2}{*}{ Parameters } & \multicolumn{3}{|c|}{ Tools } \\
\hline & & $\mathrm{B}^{*}$ & $\mathrm{~L}^{* *}$ & $\mathrm{G}^{* * *}$ \\
\hline \multirow{3}{*}{ 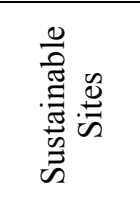 } & Light Pollution Reduction & & $\mathrm{x}$ & \\
\hline & $\begin{array}{l}\text { Connection to the Natural World - } \\
\text { Places of Respite }\end{array}$ & & $\mathrm{x}$ & \\
\hline & $\begin{array}{l}\text { Connection to the Natural World - } \\
\text { Direct Exterior Access for Patients }\end{array}$ & & $\mathrm{x}$ & \\
\hline \multirow{6}{*}{ 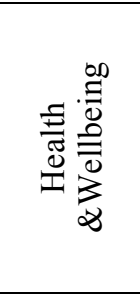 } & Day lighting & $\mathrm{x}$ & $\mathrm{x}$ & $\mathrm{x}$ \\
\hline & View Out & $\mathrm{x}$ & $\mathrm{x}$ & $\mathrm{x}$ \\
\hline & Potential for Natural Ventilation & $\mathrm{x}$ & & $\mathrm{x}$ \\
\hline & Outdoor Space & $\mathrm{x}$ & & $\mathrm{x}$ \\
\hline & Arts in Health & $\mathrm{x}$ & & \\
\hline & $\begin{array}{l}\text { Minimum Indoor Air Quality } \\
\text { Performance }\end{array}$ & & $\mathrm{x}$ & \\
\hline \multirow{3}{*}{ 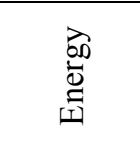 } & Optimize Energy Performance & & $\mathrm{x}$ & \\
\hline & Lighting zoning & & & $\mathrm{x}$ \\
\hline & Car park ventilation & & & $\mathrm{x}$ \\
\hline \multirow{6}{*}{ 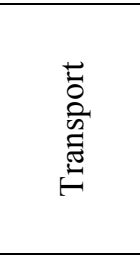 } & Proximity to amenities & $\mathrm{x}$ & & \\
\hline & Pedestrian and Cyclist Facilities & $\mathrm{x}$ & $\mathrm{x}$ & $\mathrm{x}$ \\
\hline & Maximum Car Parking Capacity & $\mathrm{x}$ & & $\mathrm{x}$ \\
\hline & Deliveries and Manoeuvring & $\mathrm{x}$ & & \\
\hline & Community Mass-transports & & & $\mathrm{x}$ \\
\hline & Transport design and planning & & & $\mathrm{x}$ \\
\hline \multirow{3}{*}{ 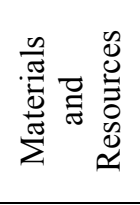 } & Compactor / Baler & $\mathrm{x}$ & & \\
\hline & $\begin{array}{l}\text { Storage and Collection of } \\
\text { Recyclables }\end{array}$ & & $\mathrm{x}$ & \\
\hline & $\begin{array}{l}\text { Resource Use - Design for } \\
\text { Flexibility }\end{array}$ & & $\mathrm{x}$ & \\
\hline \multirow{3}{*}{ 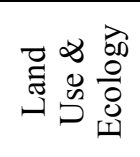 } & Reuse of Land & $\mathrm{x}$ & & $\mathrm{x}$ \\
\hline & Contaminated Land & $\mathrm{x}$ & & $\mathrm{x}$ \\
\hline & Mitigating ecological impact & $\mathrm{x}$ & & $\mathrm{x}$ \\
\hline \multirow{4}{*}{ 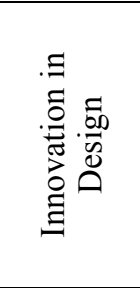 } & Innovation & $\mathrm{x}$ & & $\mathrm{x}$ \\
\hline & $\begin{array}{l}\text { Integrative Project Planning and } \\
\text { Design }\end{array}$ & & $\mathrm{x}$ & \\
\hline & $\begin{array}{l}\text { Innovation in Design: Specific } \\
\text { Title }\end{array}$ & & $\mathrm{x}$ & \\
\hline & $\begin{array}{l}\text { Integrative Project Planning and } \\
\text { Design }\end{array}$ & & $\mathrm{x}$ & \\
\hline
\end{tabular}

\section{THE ENVOLVING ROLE OF ARCHITECTURE}

\subsection{Eco-humanism in Hospitals}

Analysing the tools presented in the previous section, it is possible to see how important is the careful spaces design to the positive evaluation of several sustainability parameters. Although there are some indirect relations, it is still imperative to retain among the analysis of the categories that there are no categories dealing directly with the sociocultural dimension and functional quality. The social dimension of sustainable development is even more present in the case of hospital buildings due to the importance of the wellbeing of the patient in this kind 
of projects. On this context, it is in this category that stands out even more the importance of the spatial and volumetric organization of indoor and outdoor spaces, because its quality can give immediate and effective responses to almost all the concerns of this area of interest.

Thus, the category "Sociocultural and functional quality" that DGNB considered in its assessment tool (Table 3), and the similar one "Social, cultural and perceptual aspects" that the International SBTool considers, positively influence the concerns of spaces design quality in the architectural design phase (DGNB, 2013; iiSBE, 2013). This fact promotes the consideration of the patients and users' welfare in this type of buildings

Table 3. Criteria of the core catalogue of the DGNB tool and International SBTool (DGNB, 2013; iiSBE, 2013).

\begin{tabular}{ll}
\hline DGNB tool & International SBTool \\
\hline fuciocultural and & Social, cultural and \\
functional quality & perceptual aspects \\
\hline . Thermal comfort & . Access for mobility-impaired persons \\
. Indoor air quality & on site and with the building \\
. Acoustic comfort & . Access to direct sunlight from living \\
. Visual comfort & areas of dwelling units \\
. User influence on & . Visual privacy areas of dwelling units \\
building operation & . Access to private open space from \\
. Quality of outdoor & dwelling units \\
spaces & . Involvement of residents in project \\
. Safety and security & management \\
. Handicapped & . Compatibility of urban design with \\
accessibility & local cultural values \\
. Efficient use of & . Impact of the design on existing \\
floor area & streetscapes \\
Suitability for & . Impact of tall structure(s) on existing \\
conversion & view corridors \\
. Public access & . Quality of views from tall structures \\
. Cycling convenience & . Sway of tall buildings in high wind \\
. Design and urban & conditions \\
planning quality & . Perceptual quality of site \\
through competition & development \\
. Integration of public & . Aesthetic quality of facility exterior \\
art & . Aesthetic quality of facility interior \\
. Site features & . Access to exterior views from interior \\
\hline
\end{tabular}

It is within this context that one can speak about Eco-humanism. Eco-humanism in architecture is about having an equal concern for human and ecological wellbeing, and by its nature it touches on many uncomfortable truths (Verderber, 2010). The challenge now is to translate this unprecedented opportunity into action.

The main concerns of the space design are the humans' needs. So, the use of rating systems specifically for the hospital buildings becomes essential to include in the design phase, beyond the importance of historic preservation, and systems of interrelated hierarchies comprised of personal, institutional, and societal constructs (Rokeach, 1979).

\subsection{The architectural process}

Early environmental design initiatives were focusing only on the reduction of energy demands. Different institutes and governmental initiatives developed tools and policies to address this problem.

In 1980s and 1990s some of the initiatives began to reflect concerns about the sustainability of the construction industry c, and in 1993 the UIA/AIA Word Congress of Architects concluded that it was a bold challenge to the profession of an architect to put a broader sustainability agenda into practice (Guenther \& Vittori, 2008).

In 2000 many of these initiatives turned to incorporate sustainable design strategies as basic and fundamental in standard practice. In 2005, the American Institute of Architects (AIA) established a more aggressive position on the responsibility of design professionals, defending the position that the architects must change the professional actions and work together with the clients changing the actual paradigm of designing and operating a building (AIA, 2005).

The sustainable project requires a revolution in the way of thinking the building design. So it is important that this transformation, that across all phases of the life cycle building, will be reflected in the early stage of architectural design and in the essence of it: the design and organization of space.

If the architectural design should contain the entire patient and users' needs, environmental concerns and generate synergies among all actors of the design team, then this should directly addressed in building sustainability assessment tools. This is essential in order to support architects during the early phases of design and to recognize the efforts of an architect in designing a truly sustainable building.

Michael Lerner (2000) formulated the following question: "The question is whether healthcare professionals can begin to recognize the environmental consequences of our operations and put our own house in order" (Roberts \& Guenther, 2006). This is not a trivial question, but the foundation of all other issues that may arise around this same concern (Roberts \& Guenther, 2006). Based on this principle, Figure 2 illustrates the relationship between human health, medical treatment and environmental pollution that directly affects the mission of the health care industry. 


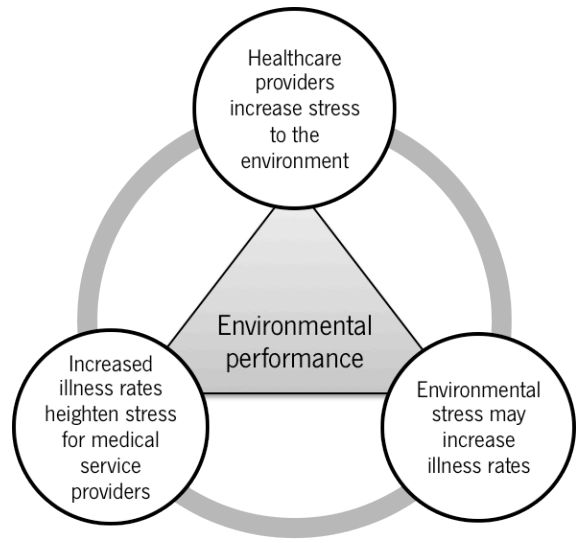

Figure 2. Relationship between environmental performance and health care (Roberts \& Guenther, 2006).

\subsection{Discussion}

It is relevant to promote and discuss the importance of the space organization to the sustainable construction and the influence of the architecture (and not only the building systems) in the Building Sustainable Assessment tools (BSA tools). It is also important that each designer involved in the development and construction of hospital buildings is able to quickly identify a set of parameters that can interfere directly, therefore that later can be considered globally to intervene in each and every one of them. All in all these tools must be bivalent, they must impose the concerns with sustainable construction but also integrate the requirements of each building and each project area, linking priorities and facilitating the integration widespread of more this concern in the different design projects. This is one aspect that can promote integration and knowledge of these tools in all project teams involved in the construction of this building typology, as well as their use in different phases of buildings life cycle.

\section{CONCLUSIONS}

The Hospital architecture has a strong social responsibility and impact on the city. Mostly due to various design requirements, these buildings are not designed and operated in a sustainable way. Based on this context it is important to include in BSA tools the best practices in architecture that should be taken into account in the design phase (to support the decisions that contribute to the building sustainability).

Although the design and organization of space encompassing always a great social responsibility, this concern is transverse to the three pillars of sustainable development (economic, social and environmental), since it allows the resolution and fit of many solutions environmentally efficient and economically viable. Based on the conclusions, future developments on BSA tools should give more weight to the- se aspects of major influence in the building life cycle performance.

\subsection{Acknowledgement}

The authors acknowledge the Portuguese Foundation for Science and Technology for the financial support under Reference SFRH/BD/77959/2011.

\subsection{References}

AIA. 2005. High-Performance Building Position Statements. Washington: AIA. Retrieved May 18, 2011, from http://www.aia.org/SiteObjects/files/HPB_position_satate ments.pdf

Boone, T. 2012, March 29. Creating a Culture of Sustainability. Leadership, Coordination and Performance

BREEAM. 2013. Home page of BREEAM. Retrieved February 20, 2013, from http://www.breeam.org

Measurement Decisions in Healthcare. Health Care Research Collaborative. 1-32.

Clark, P. \& Malone, M. 2006. What Patients Want: Designing and Delivering Health Services that Respect Personhood. In S. Marberry (Ed.), Improving Healthcare with Better Building Design (1st ed., pp. 15-35). Chicago: Health Administration Press.

DGNB. 2013, January 24. DGNB System - Criteria. Www.Dgnb-System.De. Retrieved January 24, 2013, from http://www.dgnb-system.de

Dias, M. 2004, January 25. Resíduos dos serviços de saúde e a contribuição do hospital para a preservação do meio ambiente. Academia De Enfermagem 2(2): 21-29.

GBCA, 2013. Home page of GBCA. Retrieved February 20, 2013, from http://www.gbca.org.au

Guenther, R. \& Vittori, G. 2008. Sustainable healthcare architecture. New Jersey: John Wiley \& Sons, Inc.

iiSBE. 2013. Home page of iiSBE. Retrieved February 20, 2013, from http://iisbe.org/sbtool-2012

Johnson, S. W. 2010. Summarizing Green Practices in U.S. Hospitals. Hospital Topics 88(3): 75-81.

LEED, 2013. Home page of LEED. Retrieved February 20, 2013, from https://www.leedonline.com

Roberts, G. \& Guenther, R. 2006. Environmental Responsible hospitals. In S. Marberry (Ed.), Improving Healthcare with Better Building Design (1st ed., pp. 81-107). Chicago: Health Administration Press.

Rokeach, Milton. 1979. The Nature of Human Values. New York: McGrawHill.

Sauders, T. 2008. A discussion document comparing international environmental assessment methods for buildings. breeam. Retrieved from http://www.dgbc.nl/images/uploads/rapport_vergelijking. pdf

Shaw, C. D., Kutryba, B., Braithwaite, J., Bedlicki, M. \& Warunek, A. 2010. Sustainable healthcare accreditation: messages from Europe in 2009. International Journal for Quality in Health Care 22(5): 341-350.

Short, C. A. \& Al-Maiyah, S. 2009. Design strategy for lowenergy ventilation and cooling of hospitals. Building Research \& Information 37(3): 264-292.

Verderber, S. 2010. Innovation in Hospital Architecture. New York: Routledge. 